\title{
What is the difference between the tall cell variant and the classic type of papillary thyroid carcinoma on ultrasonography?
}

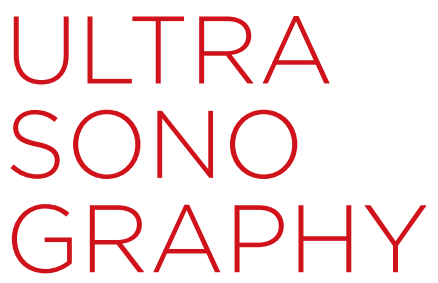

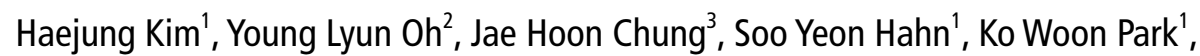 \\ Tae Hyuk Kim³, Jung Hee Shin ${ }^{1}$
}

\author{
${ }^{1}$ Department of Radiology, ${ }^{2}$ Department of Pathology, ${ }^{3}$ Department of Internal Medicine, \\ Division of Endocrinology and Metabolism, Samsung Medical Center, Sungkyunkwan
} University School of Medicine, Seoul, Korea

Purpose: The prevalence of the tall cell variant of papillary thyroid carcinoma (TCVPTC), which has a poor prognosis, has increased as its definition has been modified. We sought to investigate whether TCVPTC is different from the classic type on ultrasonography (US).

Methods: This study included 46 consecutive TCVPTC patients and 92 classic papillary thyroid carcinoma (PTC) patients who were confirmed surgically at the authors' institution. The US findings and pathologic reports of these patients were retrospectively reviewed. US features based on the Korean Thyroid Imaging Reporting and Data System, preoperative US suspicion for lymph node metastasis, and the presence of capsular location were evaluated.

Results: Univariable and multivariable analyses identified that TCVPTC showed more frequent irregular tumor margin (odds ratio $[\mathrm{OR}], 6.62 ; 95 \%$ confidence interval $[\mathrm{Cl}], 1.46$ to 30.09 ; $\mathrm{P}=0.014)$ and capsular location $(\mathrm{OR}, 4.63 ; 95 \% \mathrm{Cl}, 1.49$ to $14.41 ; \mathrm{P}=0.008)$ than classic PTC. Capsular location was an independent predictor of TCVPTC for tumors less than or equal to 1.5 $\mathrm{cm}$ in size $(\mathrm{OR}, 4.23 ; 95 \% \mathrm{Cl}, 1.12$ to $15.92 ; \mathrm{P}=0.033)$. Irregular margin was an independent predictor of TCVPTC for tumors larger than $1.5 \mathrm{~cm}(\mathrm{OR}, 10.46 ; 95 \% \mathrm{Cl}, 1.16$ to 94.48 ; $\mathrm{P}=0.037)$. Extrathyroidal extension was not significantly different between the two groups.

Conclusion: The two key features of TCVPTC on US are frequent capsular location for tumors less than or equal to $1.5 \mathrm{~cm}$ in size and the higher likelihood of an irregular margin for tumors larger than $1.5 \mathrm{~cm}$.

Keywords: Papillary thyroid carcinoma; Tall cell variant; Ultrasonography

Key points: Tall cell variant of papillary thyroid carcinoma (TCVPTC) less than or equal to $1.5 \mathrm{~cm}$ in size frequently shows a capsular location on ultrasonography (US). TCVPTC larger than $1.5 \mathrm{~cm}$ rarely shows smooth tumor margins on US.

\section{Introduction}

Papillary thyroid carcinoma (PTC) has the most favorable prognosis of all subtypes of thyroid carcinoma, with the highest 10-year relative survival rate of $98 \%$ [1]. However, PTC encompasses

\section{ORIGINAL ARTICLE}

https://doi.org/10.14366/usg.21200 pISSN: 2288-5919 • elSSN: 2288-5943 Ultrasonography 2022;41:493-501

Received: September 23, 2021

Revised: February 18, 2022

Accepted: February 21, 2022

Correspondence to: Jung Hee Shin, MD, PhD, Department of Radiology and Center for Imaging Science, Samsung Medical Center, Sungkyunkwan University School of Medicine, 81 Irwon-ro, Gangnam-gu, Seoul 06351, Korea

Tel. $+82-2-3410-2548$

Fax. +82-2-3410-0049

E-mail: jhshin11@skku.edu

This is an Open Access article distributed under the terms of the Creative Commons Attribution NonCommercial License (http://creativecommons.org/ licenses/by-nc/4.0/) which permits unrestricted noncommercial use, distribution, and reproduction in any medium, provided the original work is properly cited.

Copyright ( 2022 Korean Society of Ultrasound in Medicine (KSUM)

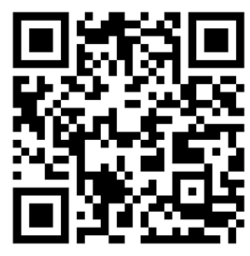

How to cite this article:

Kim H, Oh YL, Chung JH, Hahn SY, Park $\mathrm{KW}, \mathrm{Kim} \mathrm{TH}$, et al. What is the difference between the tall cell variant and the classic type of papillary thyroid carcinoma on ultrasonography?. Ultrasonography. 2022 Jul;41(3):493-501. 
several histological variants with different biological behaviors, and a disproportionate rise in aggressive PTC incidence has been reported [2-4]. Among them, the tall cell variant of PTC is the most common of the known variants with unfavorable outcomes, with reported incidence rates in the literature ranging from $4 \%$ to $17 \%$ [4-11]. Tall cell variant of papillary thyroid carcinoma (TCVPTC) was first described in 1976 and is widely known to be more aggressive than classic PTC, with greater extrathyroidal extension (ETE), a higher risk of locoregional recurrence and distant metastases, and a worse overall survival rate and prognosis $[3,4,7-15]$. Moreover, the prevalence rates of BRAF V600E and TERT promoter mutations tend to be higher in TCVPTC than in classic PTC, consistent with its aggressiveness [16-18].

Only a few studies describing the ultrasonography (US) image characteristics of TCVPTC have been published to date because of the rarity of this disease, and those studies were based on very small numbers of cases $[19,20]$. To the best of the authors' knowledge, no study has yet compared US findings between TCVPTC and the classic type of PTC. Recently, the diagnostic criteria for TCVPTC were modified in the 2017 World Health Organization (WHO) Classification of Tumors of Endocrine Organs, with looser requirements for both the height of tumor cells and the percentage of tumor demonstrating a tall cell morphology [21]. This change in criteria might have resulted in a significant increase in the percentage of tumors classified as TCVPTC [9]. As the American Thyroid Association (ATA) characterizes TCVPTC as an intermediaterisk tumor that should undergo total thyroidectomy and suggests that radioactive iodine treatment should be considered, the increase in the number of tumors diagnosed as TCVPTC has significant clinical implications $[9,22]$. Moreover, aggressive PTC subtypes warrant profound understanding because they constitute a growing portion of the total cases of PTC and a higher proportion of instances of cancer-associated mortality [3].

Given the recently updated diagnostic criteria for TCVPTC and the consequent increase in its incidence, it may now be possible to collect a relatively larger number of cases for analysis. Therefore, we aimed to investigate whether TCVPTC is different from the classic type of PTC on US.

\section{Materials and Methods}

\section{Compliance with Ethical Standards}

This retrospective study was approved by the Institutional Review Board and Ethics Committee of Samsung Medical Center (2020-08$128)$, and the requirement for informed consent was waived.

\section{Patients}

From January 2001 to December 2019, a total of 50 consecutive patients were surgically confirmed to have TCVPTC at the authors' institution. Among them, three patients were excluded due to unavailable US images and one patient was excluded because the size of the tumor was too small to be seen on the US images and was incidentally confirmed in the pathology report after surgery. To collect classic PTC patients, 109 consecutive patients who were surgically confirmed to have PTC at the authors' institution between October 2017 and December 2017 were reviewed. Sixteen patients with PTC variants were excluded, as well as one with a discrepancy in the tumor size between the pathology report and US image, making it impossible to evaluate the correlation between imaging findings and pathology. Finally, a total of 138 patients, including 46 with TCVPTC and 92 with classic PTC, were included.

\section{US Examination, US Features, and Data Analysis}

Sonography was performed with a $7-$ to $12-\mathrm{MHz}$ linear array transducer (HDI 5000, Philips Healthcare, Best, the Netherlands) or a 5- to 12-MHz linear array transducer (iU22, Phillips Healthcare). Real-time sonography was performed by one of 25 radiologists with 1-20 years of experience in thyroid imaging. Grayscale images always included both longitudinal and transverse planes for regions of interest.

Two radiologists (J.H.S. and H.K.) retrospectively reviewed preoperative US scans and analyzed image findings, coming to a consensus regarding their final details. Based on the revised 2021 Korean Thyroid Imaging Reporting and Data System (K-TIRADS), all thyroid nodules were evaluated for composition, echogenicity, orientation, margin, and echogenic foci [23]. The composition was categorized as solid (no obvious cystic component), predominantly solid ( $\leq 50 \%$ of the cystic portion), predominantly cystic $(>50 \%$ of the cystic portion), cystic (no obvious solid content), or spongiform (microcystic changes $>50 \%$ of solid component). The echogenicity was categorized as markedly hypoechoic, mildly hypoechoic, isoechoic, or hyperechoic. The orientation was classified as parallel or nonparallel. The margin was classified as irregular, smooth, or ill-defined. When the margin was obviously discernible, but non-smooth edges with spiculations or microlobulations, it was categorized as irregular. When the margin was obviously discernible with a smooth edge, it was categorized as smooth. An ill-defined margin was defined as a margin that was poorly demarcated and could not be obviously differentiated from the adjacent thyroid tissue. If echogenic foci were present, they were classified as microcalcifications ( $\leq 1 \mathrm{~mm}$ in size), macrocalcifications ( $>1 \mathrm{~mm}$ in size with posterior shadowing), rim calcifications, or intracystic echogenic foci with the comet-tail artifact. For the final K-TIRADS 
categorization, thyroid nodules were classified into the following five groups: category 1, no nodule; category 2 , benign nodule (isohyperechoic spongiform, pure cyst, or partially cystic nodule with intracystic echogenic foci and the comet-tail artifact); category 3, low-suspicion nodule (partially cystic or isohyperechoic nodule without any of the three suspicious US features-i.e., punctate echogenic foci, nonparallel orientation, or irregular margin); category 4, intermediate-suspicion nodule (solid hypoechoic nodule without any of the three aforementioned suspicious US features or a partially cystic, isohyperechoic nodule with any of the three aforementioned suspicious US features, or an entirely calcified nodule); and category 5, high-suspicion nodule (solid hypoechoic nodule with any of the three aforementioned suspicious US features). In addition, the presence or absence of preoperative US suspicion for lateral lymph node metastasis and tumor location in the thyroid gland on preoperative US was assessed. Lymph nodes were considered sonographically suspicious if at least one of the following four sonographic criteria was met: cystic change, echogenic foci (calcifications), cortical hyperechogenicity (focal/ diffuse), or abnormal vascularity (peripheral/diffuse) according to the 2021 K-TIRADS. The tumor location was classified as capsular or intraparenchymal. The location was defined as intraparenchymal was defined when normal parenchyma surrounded the tumor and no part of the tumor was in contact with the thyroid capsule. Capsular location, a concept contrasting with intraparenchymal location, was defined as when the tumor showed contact with the thyroid capsule regardless of the percentage of the perimeter of the tumor that contacted the capsule, or when a tumor crossed the thyroid capsule, including capsular protrusion (Fig. 1). Capsular location is a concept with a broader meaning than US findings predicting ETE, as it includes tumors with only focal contact with the thyroid capsule, which does not always suggest ETE. We performed a subgroup analysis based on a size cutoff of $1.5 \mathrm{~cm}$ because we assumed that capsular location could be affected by the size of the tumor. In cases with more than one nodule, the largest nodule was assessed as the index tumor.

\section{Pathological Analysis}

The pathology reports of all patients were reviewed for tumor size, the final status of central and lateral lymph node metastasis, ETE, lymph vessel invasion, blood vessel invasion, preoperative fineneedle aspiration (FNA) or core needle biopsy (CNB) results using the Bethesda category, and multifocality. Of 46 TCVPTC cases, 17 patients who underwent surgery before the revision of the diagnostic criteria in 2017 were pathologically analyzed based on the 2004 WHO Classification of Tumors of Endocrine Organs and diagnosed as having TCVPTC when the cancer cells were three

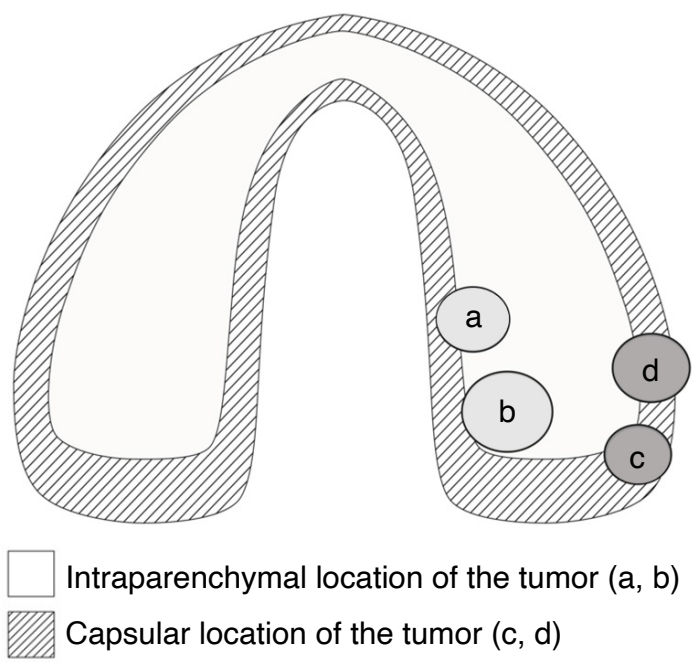

Fig. 1. The tumor location was classified as capsular or intraparenchymal. The location was defined as intraparenchymal when normal parenchyma surrounded the tumor and no part of the tumor was in contact with the thyroid capsule $(a, b) . A$ is closer to the capsule than b, but does not touch it. Capsular location, a concept contrasting with intraparenchymal location, was defined as a tumor showing contact with the thyroid capsule regardless of the percentage of the perimeter of the tumor that contacted the capsule (c), or when a tumor crossed the thyroid capsule, including capsular protrusion (d). The dashed-line zone denotes capsular location, which was a disproportionately common finding of the tall cell variant of papillary thyroid carcinoma. Capsular location is a concept with a broader meaning than ultrasonography findings predicting extrathyroidal extension (ETE), as it includes tumors with only focal contact with the thyroid capsule, which does not always suggest ETE.

times taller than wide and tall cells comprised more than 50\% of all cancer cells. However, in 29 patients who received surgery after the change in the diagnostic criteria in 2017, TCVPTC was diagnosed as such when more than $30 \%$ of the cells were tall cells measuring two to three times taller than wide, based on the 2017 WHO Classification [21]. According to the seventh edition of the American Joint Committee on Cancer (AJCC) Cancer Staging Manual released in 2010, ETE was classified as minimal (extension to the sternothyroid muscle or perithyroid soft tissue) or extensive (extension to the subcutaneous soft tissue, larynx, esophagus, trachea, recurrent laryngeal nerve, prevertebral fascia, mediastinal vessels, or carotid arteries). Instead, the eighth edition of the AJCC Cancer Staging Manual released in 2017 defined ETE as minor (detected only on histological examination) or gross (extension to the sternohyoid, sternothyroid, thyrohyoid, or omohyoid muscles, subcutaneous soft tissue, larynx, esophagus, trachea, recurrent laryngeal nerve, prevertebral fascia, mediastinal vessels, or carotid arteries) [24]. Although patients who underwent surgery before 
2017 were included, the pathological ETE of all included cases was collectively analyzed based on the eighth edition.

\section{Statistical Analysis}

All categorical variables were analyzed using the chi-square or Fisher exact test and continuous variables were assessed using the Student t-test and Wilcoxon rank-sum test. Post-hoc analysis was conducted for pairwise multiple comparisons with the Bonferroni correction. Logistic regression was used for multivariable analysis. For all statistical methods, a P-value of less than 0.05 was considered to indicate statistical significance, and the statistical analysis was conducted using SAS version 9.4 (SAS Institute, Cary, NC, USA).

\section{Results}

The clinicopathologic characteristics are summarized in Table 1. A total of 138 patients, including 46 TCVPTC patients (mean age, $50.43 \pm 15.52$ years; range, 34 to 83 years) and 92 classic PTC patients (mean age, $45.73 \pm 12.54$ years; range, 16 to 70 years) were finally included. Although the mean age of the TCVPTC patients was higher, the difference was not statistically significant $(P=0.057)$. Among the 138 patients, 47 were men (16 TCVPTC and 31 classic cases, respectively) and 91 were women (30 TCVPTC and 61 classic cases, respectively), and the sex distribution was not significantly different between the two groups $(P=0.899)$. The mean tumor size was larger in TCVPTC, but with a non-significant difference (TCVPTC group: $1.76 \pm 1.30 \mathrm{~cm}$ vs. classic PTC group: $1.43 \pm 0.78 \mathrm{~cm}$;
$\mathrm{P}=0.430$ ). The rate of pathologically proven ETE was not significantly different between the two groups $(P=0.346)$. Central and lateral lymph node metastasis, lymph vessel invasion, blood vessel invasion, preoperative FNA or CNB results using the Bethesda category, and multifocality were also not significantly different between the groups $(P=0.225, P=0.113, P=0.060, P=0.580, P=0.299$, and $P=0.176$, respectively).

The US imaging characteristics of the two groups are summarized in Table 2. The tumor margin on preoperative US showed a statistically significant difference between the TCVPTC and classic PTC groups ( $\mathrm{P}=0.002)$. In the post-hoc analysis for multiple comparisons, smooth margins were significantly rarer and irregular margins were significantly more frequent in TCVPTC than in classic PTC (4.3\% vs. $25.0 \%$ and $93.5 \%$ vs. $75.0 \%, P=0.009)$ (Fig. 2). The tumor location in the thyroid gland on preoperative US was also significantly different between the two groups, with TCVPTC patients more frequently presenting a capsular location than classic PTC patients (89.1\% vs. 67.4\%, P=0.002) (Fig. 2). Although preoperative suspicion for lateral lymph node metastasis was more common in TCVPTC than in classic PTC, the difference was statistically not significant ( $34.8 \%$ vs. $22.7 \%, P=0.051)$. There were also no statistically significant differences in terms of composition, echogenicity, orientation, echogenic foci, or K-TIRADS classification between TCVPTC and classic PTC ( $P=0.401, P=0.231, P=0.335$, $P=0.797$, and $P=0.119$, respectively).

The results of subgroup analyses regarding the US imaging characteristics of the two groups according to tumor size are

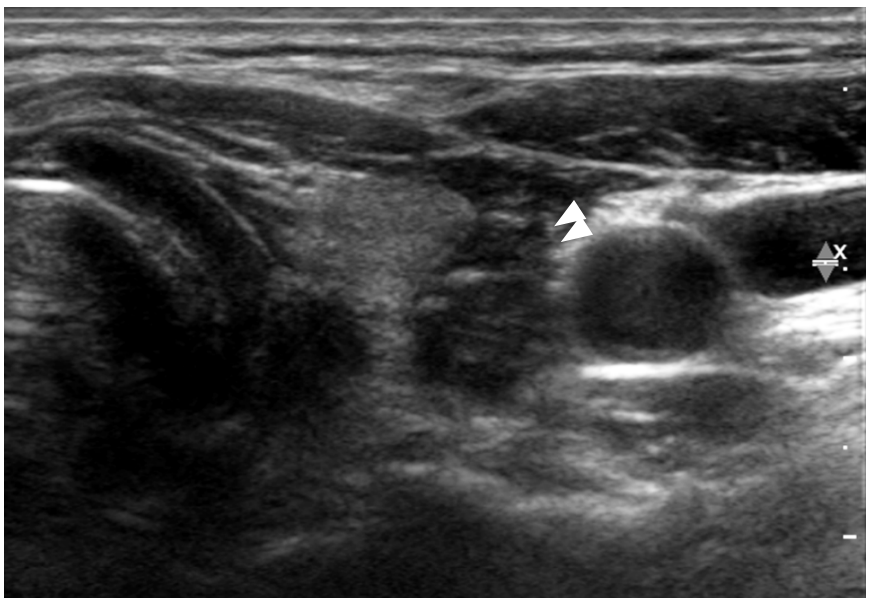

A

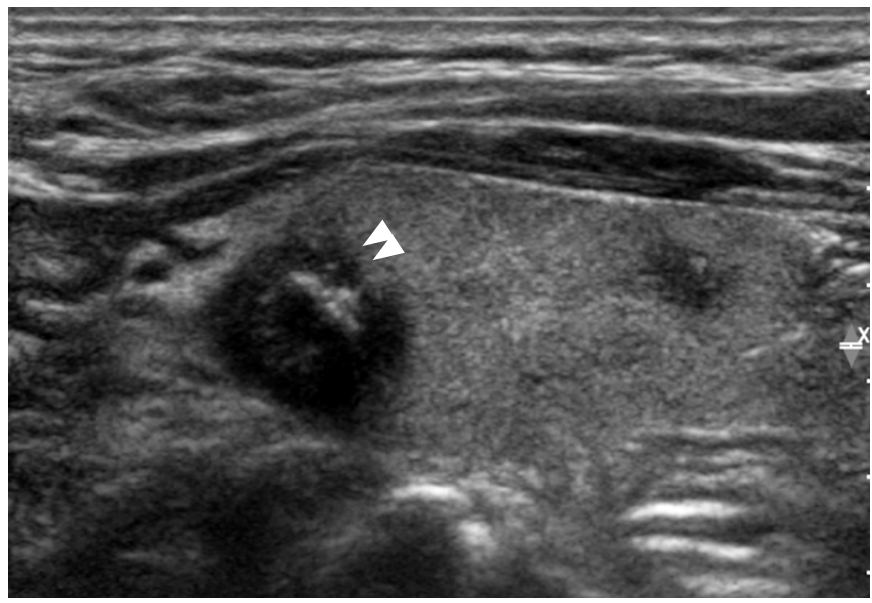

B

Fig. 2. A 63-year-old woman with tall cell variant papillary thyroid carcinoma in the left thyroid lobe.

Transverse (A) and longitudinal (B) ultrasonography show a 1.2-cm solid mass (arrowheads) with marked hypoechogenicity, irregular margin, nonparallel orientation, microcalcifications, and capsular location. This mass was classified as a high-suspicion nodule (K-TIRADS 5). In the final pathology report after surgery, minor extrathyroidal extension was present. K-TIRADS, Korean Thyroid Imaging Reporting and Data System. 
Table 1. Clinicopathologic characteristics of the study population

\begin{tabular}{|c|c|c|c|}
\hline Variable & Classic PTC (n=92) & TCVPTC $(n=46)$ & P-value \\
\hline Age (year) & $45.73 \pm 12.54$ & $50.43 \pm 15.52$ & 0.057 \\
\hline Sex & & & 0.899 \\
\hline Male & $31(33.7)$ & $16(34.8)$ & \\
\hline Female & $61(66.3)$ & $30(65.2)$ & \\
\hline Tumor size (cm) & $1.43 \pm 0.78$ & $1.76 \pm 1.30$ & 0.430 \\
\hline $\begin{array}{l}\text { Central lymph node } \\
\text { metastasis }\end{array}$ & & & 0.225 \\
\hline No & $44(47.8)$ & $17(37.0)$ & \\
\hline Yes & $48(52.2)$ & $29(63.0)$ & \\
\hline $\begin{array}{l}\text { Lateral lymph node } \\
\text { metastasis }\end{array}$ & & & 0.113 \\
\hline No & 75 (81.5) & $32(69.6)$ & \\
\hline Yes & $17(18.5)$ & $14(30.4)$ & \\
\hline $\begin{array}{l}\text { Extrathyroidal } \\
\text { extension }\end{array}$ & & & 0.346 \\
\hline No & $28(30.4)$ & $10(21.7)$ & \\
\hline Minor & $50(54.4)$ & $25(54.4)$ & \\
\hline Gross & $14(15.2)$ & $11(23.9)$ & \\
\hline $\begin{array}{l}\text { Lymph vessel } \\
\text { invasion }^{\text {a) }}\end{array}$ & & & 0.060 \\
\hline No & $82(89.1)$ & $29(76.3)$ & \\
\hline Yes & $10(10.9)$ & $9(23.7)$ & \\
\hline Blood vessel invasion ${ }^{\text {a) }}$ & & & 0.580 \\
\hline No & $90(97.8)$ & $36(94.7)$ & \\
\hline Yes & $2(2.2)$ & $2(5.3)$ & \\
\hline $\begin{array}{l}\text { Preoperative FNA or } \\
\text { CNB results using the } \\
\text { Bethesda category }\end{array}$ & & & 0.299 \\
\hline Non-diagnostic (I) & 0 & 0 & \\
\hline Benign (II) & 0 & 0 & \\
\hline AUS/FLUS (III) & $3(3.3)$ & $4(8.7)$ & \\
\hline FN/SFN (IV) & 0 & 0 & \\
\hline $\begin{array}{l}\text { Suspicious for } \\
\text { malignancy (V) }\end{array}$ & $33(35.8)$ & $13(28.3)$ & \\
\hline Malignant (VI) & $56(60.9)$ & $29(63.0)$ & \\
\hline Multifocality & & & 0.176 \\
\hline No & $59(64.1)$ & $24(52.2)$ & \\
\hline Yes & $33(35.9)$ & $22(47.8)$ & \\
\hline
\end{tabular}

Values are presented as mean \pm SD or number (\%).

PTC, papillary thyroid carcinoma; TCVPTC, tall cell variant papillary thyroid carcinoma; FNA, fine-needle aspiration; CNB, core needle biopsy; AUS/FLUS, atypia of undetermined significance/follicular lesion of undetermined significance; FN/SFN, follicular neoplasm/suspicion for a follicular neoplasm.

${ }^{a}$ Evaluation of lymph vessel and blood vessel invasion was not possible in eight cases of TCVPTC because the relevant information was not described in the pathology report.
Table 2. Ultrasonographic imaging characteristics of classic PTC and TCVPTC

\begin{tabular}{|c|c|c|c|}
\hline Variable & Classic PTC $(n=92)$ & TCVPTC $(n=46)$ & P-value \\
\hline Composition & & & 0.401 \\
\hline Solid & $88(95.7)$ & $46(100)$ & \\
\hline Predominantly solid & $2(2.2)$ & 0 & \\
\hline Predominantly cystic & $2(2.2)$ & 0 & \\
\hline Echogenicity & & & 0.231 \\
\hline Markedly hypoechoic & $34(37.0)$ & $24(52.2)$ & \\
\hline Mildly hypoechoic & $43(46.7)$ & $16(34.8)$ & \\
\hline Isoechoic & $15(16.3)$ & $6(13.0)$ & \\
\hline Orientation & & & 0.335 \\
\hline Parallel & $48(52.2)$ & $20(43.5)$ & \\
\hline Nonparallel & $44(47.8)$ & $26(56.5)$ & \\
\hline Margin & & & $0.002^{\mathrm{a})}$ \\
\hline Irregular & $69(75.0)$ & $43(93.5)$ & \\
\hline Smooth & $23(25.0)$ & $2(4.3)$ & \\
\hline III-defined & 0 & $1(2.2)$ & \\
\hline Echogenic foci & & & 0.797 \\
\hline No & $25(27.2)$ & $12(26.1)$ & \\
\hline Microcalcification & $53(57.6)$ & $30(65.2)$ & \\
\hline Macrocalcification & $10(10.9)$ & $3(6.5)$ & \\
\hline Rim calcification & $4(4.3)$ & $1(2.2)$ & \\
\hline K-TIRADS & & & 0.119 \\
\hline 3 (low suspicion) & $1(1.1)$ & 0 & \\
\hline 4 (intermediate suspicion) & $24(26.1)$ & $6(13.0)$ & \\
\hline 5 (high suspicion) & $67(72.8)$ & $40(87.0)$ & \\
\hline Location & & & $0.002^{b)}$ \\
\hline Intraparenchymal & $30(32.6)$ & $5(10.9)$ & \\
\hline Capsular & $62(67.4)$ & $41(89.1)$ & \\
\hline $\begin{array}{l}\text { Suspicion for lateral lymph } \\
\text { node metastasis }\end{array}$ & & & 0.051 \\
\hline No & 74 (80.4) & $30(65.2)$ & \\
\hline Yes & $18(22.7)$ & $16(34.8)$ & \\
\hline
\end{tabular}

Values are presented as number (\%).

PTC, papillary thyroid carcinoma; TCVPTC, tall cell variant papillary thyroid carcinoma; K-TIRADS, Korean Thyroid Imaging Reporting and Data System.

${ }^{a}$ Multiple comparisons among three categories were conducted using the chi-square and Fisher exact test with the Bonferroni correction. The P-values for all pairwise comparisons (irregular vs. smooth, irregular vs. ill-defined, and smooth vs. ill-defined) were 0.009 , $>0.99$, and 0.345 , respectively. ${ }^{b} \mathrm{P}<0.05$ was considered to indicate statistical significance. 
shown in Table 3. In tumors less than or equal to $1.5 \mathrm{~cm}$ in size, TCVPTC had a capsular location significantly more frequently than classic PTC ( $85.7 \%$ vs. $59.1 \%, P=0.012)$. Although the overall $\mathrm{P}$-value for the margin was less than 0.05 , the difference was not statistically significant when pairwise multiple comparisons were conducted (P-values for irregular vs. smooth, irregular vs. ill-defined, and smooth vs. ill-define $=0.186,0.975$, and 0.354 , respectively). According to the K-TIRADS classification, high-suspicion nodules were more frequent in TCVPTC than in classic PTC $(92.9 \%$ vs. $74.7 \%, P=0.042$ ). For tumors larger than $1.5 \mathrm{~cm}$, margin was the only significantly different US finding between the two groups, with TCVPTC showing more frequent irregular margins and rarer smooth margins than classic PTC ( $94.4 \%$ vs. $61.9 \%$ and $5.6 \%$ vs. $38.1 \%$, respectively; $\mathrm{P}=0.023$ ). The distribution of capsular location was not significantly different, as $94.4 \%$ of TCVPTC and $95.2 \%$ of classic PTC cases larger than $1.5 \mathrm{~cm}$ showed a capsular location ( $P>0.99$ ).

Table 3. Ultrasonographic imaging characteristics of classic PTC and TCVPTC according to tumor size

\begin{tabular}{|c|c|c|c|c|c|c|}
\hline \multirow{2}{*}{ Variable } & \multicolumn{3}{|c|}{ Tumor size $\leq 1.5 \mathrm{~cm}$} & \multicolumn{3}{|c|}{ Tumor size $>1.5 \mathrm{~cm}$} \\
\hline & Classic PTC & TCVPTC & P-value & Classic PTC & TCVPTC & P-value \\
\hline Composition & & & $>0.99$ & & & 0.490 \\
\hline Solid & $69(97.2)$ & $28(100.0)$ & & $19(90.5)$ & $18(100)$ & \\
\hline Predominantly solid & $2(2.8)$ & 0 & & $2(9.5)$ & 0 & \\
\hline Predominantly cystic & 0 & 0 & & 0 & 0 & \\
\hline Echogenicity & & & 0.123 & & & 0.744 \\
\hline Markedly hypoechoic & $27(38.0)$ & $17(60.7)$ & & $7(33.3)$ & $7(38.9)$ & \\
\hline Mildly hypoechoic & $36(50.7)$ & $9(32.1)$ & & $7(33.3)$ & $7(38.9)$ & \\
\hline Isoechoic & $8(11.3)$ & $2(7.1)$ & & $7(33.3)$ & $4(22.2)$ & \\
\hline Orientation & & & 0.272 & & & 0.477 \\
\hline Parallel & 34 (47.9) & $10(35.7)$ & & $14(66.7)$ & $10(55.6)$ & \\
\hline Nonparallel & $37(52.1)$ & $18(64.3)$ & & $7(33.3)$ & $8(44.4)$ & \\
\hline Margin & & & $0.027^{\mathrm{a})}$ & & & $0.023^{b)}$ \\
\hline Irregular & $56(78.9)$ & $26(92.8)$ & & $13(61.9)$ & $17(94.4)$ & \\
\hline Smooth & $15(21.1)$ & $1(2.6)$ & & $8(38.1)$ & $1(5.6)$ & \\
\hline III-defined & 0 & $1(2.6)$ & & 0 & 0 & \\
\hline Echogenic foci & & & 0.954 & & & $>0.99$ \\
\hline No & $21(29.6)$ & $9(32.1)$ & & $4(19.1)$ & $3(16.7)$ & \\
\hline Microcalcification & $39(54.9)$ & $16(57.2)$ & & $14(66.7)$ & $14(77.7)$ & \\
\hline Macrocalcification & $8(11.3)$ & $2(7.1)$ & & $2(9.5)$ & $1(5.6)$ & \\
\hline Rim calcification & $3(4.2)$ & $1(3.6)$ & & $1(4.8)$ & 0 & \\
\hline K-TIRADS & & & $0.042^{b)}$ & & & 0.849 \\
\hline 3 (low suspicion) & 0 & 0 & & $1(4.7)$ & 0 & \\
\hline 4 (intermediate suspicion) & $18(25.3)$ & $2(7.1)$ & & $6(28.6)$ & $4(22.2)$ & \\
\hline 5 (high suspicion) & $53(74.7)$ & $26(92.9)$ & & $14(66.7)$ & $14(77.8)$ & \\
\hline Location & & & $0.012^{b)}$ & & & $>0.99$ \\
\hline Intraparenchymal & $29(40.9)$ & $4(14.3)$ & & $1(4.8)$ & $1(5.6)$ & \\
\hline Capsular & $42(59.1)$ & $24(85.7)$ & & $20(95.2)$ & $17(94.4)$ & \\
\hline Suspicion for lateral lymph node metastasis & & & 0.065 & & & 0.843 \\
\hline No & $63(88.7)$ & $20(71.4)$ & & $11(52.4)$ & $10(55.6)$ & \\
\hline Yes & $8(11.3)$ & $8(28.6)$ & & $10(47.6)$ & $8(44.4)$ & \\
\hline
\end{tabular}

Values are presented as number (\%).

PTC, papillary thyroid carcinoma; TCVPTC, tall cell variant papillary thyroid carcinoma; K-TIRADS, Korean Thyroid Imaging Reporting and Data System.

a) Multiple comparisons among three categories were conducted using the Fisher exact test with the Bonferroni correction. The P-values for all pairwise comparisons (irregular vs. smooth, irregular vs. ill-defined, and smooth vs. ill-defined) were $0.186,0.975$, and 0.354 , respectively. ${ }^{\text {b) }} \mathrm{P}<0.05$ was considered to indicate statistical significance. 
Multivariable analysis identified that an irregular tumor margin $(P=0.014)$ and capsular location ( $P=0.008)$ on preoperative US were independent predictors of TCVPTC (Table 4). The odds ratio (OR) for irregular tumor margin was 6.62 (95\% confidence interval [CI], 1.46 to 30.09), and that for capsular location was 4.63 (95\% $\mathrm{Cl}, 1.49$ to 14.41$)$. In the subgroup analysis, capsular location was the only significant US finding for predicting TCVPTC in tumors less than or equal to $1.5 \mathrm{~cm}$ in size $(\mathrm{OR}, 4.23 ; 95 \% \mathrm{Cl}, 1.12$ to 15.92 ; $\mathrm{P}=0.033)$. However, irregular tumor margin was the only significant US predictor of TCVPTC in tumors larger than $1.5 \mathrm{~cm}(\mathrm{OR}, 10.46$; $95 \% \mathrm{Cl}, 1.16$ to $94.48 ; \mathrm{P}=0.037)$.

\section{Discussion}

It is well-known that TCVPTC has a poor prognosis, with more aggressive behavior than classic PTC, and some studies have reported that the histologic subtype itself is an independent factor associated with increased mortality, regardless of recognized factors such as ETE and nodal metastasis [3,11,13-15]. However, due to its rarity and the variable definitions for diagnosis offered by investigators, TCVPTC remains sparsely defined and largely understudied. Unsurprisingly, only a few studies regarding the US imaging findings of TCVPTC have been reported, despite US being the first-line imaging modality for the diagnosis of thyroid cancer. Recently, an upsurge in the incidence of aggressive PTC has been reported as either attributable to a fundamental increase in cancer development or from an increasing awareness of the condition among pathologists [3]. In accordance with the recently revised diagnostic criteria of TCVPTC in 2017, it was possible to collect a relatively large number of TCVPTC cases. To the best of the authors' knowledge, this is the first study that compared US image findings of TCVPTC with those of classic PTC using a large number of cases.

Choi et al. [19] first reported the sonographic features of 10 TCVPTC cases from three tertiary centers. Their study showed

Table 4. Multivariate logistic regression analysis of independent US imaging findings predicting TCVPTC

\begin{tabular}{lcc}
\hline \multicolumn{1}{c}{ US finding } & OR $(95 \% \mathrm{Cl})$ & P-value \\
\hline All tumor & & \\
Irregular tumor margin & $6.62(1.46-30.09)$ & 0.014 \\
$\quad$ Capsular location & $4.63(1.49-14.41)$ & 0.008 \\
$\begin{array}{l}\text { Tumor size } \leq 1.5 \mathrm{~cm} \\
\quad \text { Capsular location }\end{array}$ & $4.23(1.12-15.92)$ & 0.033 \\
$\begin{array}{l}\text { Tumor size }>1.5 \mathrm{~cm} \\
\quad \text { Irregular tumor margin }\end{array}$ & $10.46(1.16-94.48)$ & 0.037 \\
\hline $\begin{array}{l}\text { US, ultrasonography; TCVTC, tall cell variant papillary thyroid carcinoma; OR, odds } \\
\text { ratio; Cl, confidence interval. }\end{array}$ &
\end{tabular}

that TCVPTC often appears on US as microlobulated, markedly hypoechoic nodules with microcalcifications and ETE and is always associated with lymph node metastasis. However, due to the small number of cases available, they were unable to determine statistically significant differences in comparison with classic PTC. Meanwhile, Baek et al. [20] reported that US features were not useful for distinguishing the various subtypes of PTC, but this was based on an analysis performed using only five cases of TCVPTC.

We found that TCVPTC less than or equal to $1.5 \mathrm{~cm}$ in size was marked by a more frequent capsular location than classic PTC, and this was the only independent factor predicting TCVPTC in the multivariable subgroup analysis. However, tumor location was not significantly different between the two groups when the tumor size was larger than $1.5 \mathrm{~cm}$. This result is probably because larger tumors have a higher probability of a capsular location. In fact, 94.4\% (17 of 18) of all tumors larger than $1.5 \mathrm{~cm}$ showed a capsular location. Although capsular location was more frequent in TCVPTC less than or equal to $1.5 \mathrm{~cm}$ in size, it did not lead to significant difference in the pathologically proven ETE between the two groups in this study. A possible explanation is that the definition of "capsular location" is broader than the US findings predicting ETE, as it includes tumors with only focal contact with the thyroid capsule, which does not always suggest ETE. In fact, ETE was also not significantly different between the two groups regardless of tumor size. This may be due to the fact that K-TIRADS was applied in 2016 and that small PTCs of less than $1 \mathrm{~cm}$ in size diagnosed in 2017 did not undergo surgery, especially if they had an intraparenchymal location. As a result, the classic PTCs included in our study might have shown a relatively higher rate of ETE. Moreover, due to its rarity, there have been no studies on TCVPTC reflecting the revised 2017 WHO classification until recently, so further studies with larger study populations are required.

In this study, TCVPTC cases larger than $1.5 \mathrm{~cm}$ showed smooth tumor margins only rarely and tended to manifest as irregularmargin tumors, unlike classic PTC. This is consistent with the results of Choi et al. [19], who reported that TCVPTC often appeared on US as microlobulated tumors. According to the K-TIRADS classification, irregular margins are mostly found in infiltrating malignant tumors and this US feature is strongly predictive of malignancy [25]. Lee et al. [26] reported that an infiltrative tumor margin of papillary thyroid microcarcinoma is a predictor of invasiveness. The low frequency of smooth tumor margins in TCVPTC may reflect the aggressive nature of this cancer.

The two key US imaging findings of TCVPTC that we found to be significantly different from those of classic PTC are both good preoperative predictors of its poor prognosis and aggressive nature. According to the K-TIRADS system, decision-making concerning 
the FNA of subcentimeter high-suspicion nodules depends upon the management strategy of thyroid microcarcinomas, and FNA is recommended in patients with poor prognostic factors, including suspected cervical lymph node metastases, obvious ETE to adjacent structures, confirmed distant metastases, or suspected medullary thyroid cancer [23]. However, a subcapsular location of the tumor is also known to be associated with aggressive behavior in papillary thyroid microcarcinoma, and it may be on the same spectrum of disease progression with ETE, as a subcapsular location may progress to ETE [26-29]. The results of the present study are compatible with those of earlier studies in terms of different therapeutic strategies being required when dealing with aggressive variants of PTC that tend to show more preoperative US findings suggestive of ETE. Patients who receive an early and accurate diagnosis can be linked to appropriate treatment, improving their prognosis [8]. In 2015, the ATA guidelines adopted active surveillance as an alternative to immediate surgery in select patients with low-risk PTC [22]. At this point, as the rate of active surveillance is increasing, preventing overdiagnosis and overtreatment of very low-risk PTCs is one of the most important issues, while predicting the aggressive variant of PTC is similarly important and is likely a necessary task [30,31]. Moreover, optimizing specific therapeutic strategies based on different variants will become more crucial as the incidence of these variants increases [3].

The present study has certain limitations. Because cases were collected for a long period of time, the diagnostic criteria of TCVPTC from both before and after the 2017 WHO revision were used. A comparative analysis of the two eras was not feasible due to the limited number of cases. Moreover, it was practically impossible to review the pathologic specimens of all included cases, as most of the slides were unavailable for reanalysis and more serious bias could have occurred as the old criteria were stricter than the revised criteria, implying that a significant proportion of TCVPTC might have been omitted.

In conclusion, the two key features of TCVPTC on US are a frequent capsular location for tumors less than or equal to $1.5 \mathrm{~cm}$ in size and a higher likelihood of an irregular margin for tumors larger than $1.5 \mathrm{~cm}$.

ORCID: Haejung Kim: https://orcid.org/0000-0003-4855-9711; Young Lyun Oh: https://orcid.org/0000-0002-9127-4642; Jae Hoon Chung: https://orcid.org/00000002-9563-5046; Soo Yeon Hahn: https://orcid.org/0000-0002-4099-1617; Ko Woon Park: https://orcid.org/0000-0001-9386-5772; Tae Hyuk Kim: https://orcid.org/00000002-7975-2437; Jung Hee Shin: https://orcid.org/0000-0001-6435-7357

\section{Author Contribution}

Conceptualization: Kim H, Oh YL, Chung JH, Hahn SY, Park KW, Kim
TH, Shin JH. Data acquisition: Kim H, Oh YL, Chung JH, Hahn SY, Park KW, Kim TH, Shin JH. Data analysis or interpretation: Kim H, Oh YL, Chung JH, Hahn SY, Park KW, Kim TH, Shin JH. Drafting of the manuscript: Kim H, Shin JH. Critical revision of the manuscript: Kim H, Shin JH. Approval of the final version of the manuscript: all authors.

\section{Conflict of Interest}

No potential conflict of interest relevant to this article was reported.

\section{References}

1. Gilliland FD, Hunt WC, Morris DM, Key CR. Prognostic factors for thyroid carcinoma. A population-based study of 15,698 cases from the Surveillance, Epidemiology and End Results (SEER) program 1973-1991. Cancer 1997;79:564-573.

2. Silver $C E$, Owen RP, Rodrigo JP, Rinaldo A, Devaney KO, Ferlito A. Aggressive variants of papillary thyroid carcinoma. Head Neck 2011;33:1052-1059.

3. Ho AS, Luu M, Barrios L, Chen I, Melany M, Ali N, et al. Incidence and mortality risk spectrum across aggressive variants of papillary thyroid carcinoma. JAMA Oncol 2020;6:706-713.

4. Xu J, Zhang Y, Liu J, Qiu S, Wang M. A population-based study of the three major variants of papillary thyroid carcinoma. J Int Med Res 2021;49:300060520984618.

5. Ghossein R, Livolsi VA. Papillary thyroid carcinoma tall cell variant. Thyroid 2008;18:1179-1181.

6. Ghossein RA, Leboeuf R, Patel KN, Rivera M, Katabi N, Carlson $D L$, et al. Tall cell variant of papillary thyroid carcinoma without extrathyroid extension: biologic behavior and clinical implications. Thyroid 2007;17:655-661.

7. Longheu A, Canu GL, Cappellacci F, Erdas E, Medas F, Calo PG. Tall cell variant versus conventional papillary thyroid carcinoma: a retrospective analysis in 351 consecutive patients. J Clin Med 2020;10:70.

8. Coca-Pelaz A, Shah JP, Hernandez-Prera JC, Ghossein RA, Rodrigo $J \mathrm{~J}$, Hartl DM, et al. Papillary thyroid cancer-aggressive variants and impact on management: a narrative review. Adv Ther 2020;37:3112-3128.

9. Wong KS, Higgins SE, Marqusee E, Nehs MA, Angell T, Barletta JA. Tall cell variant of papillary thyroid carcinoma: impact of change in WHO definition and molecular analysis. Endocr Pathol 2019:30:4348.

10. Villar-Taibo R, Peteiro-Gonzalez D, Cabezas-Agricola JM, Aliyev E, Barreiro-Morandeira F, Ruiz-Ponte C, et al. Aggressiveness of the tall cell variant of papillary thyroid carcinoma is independent of the tumor size and patient age. Oncol Lett 2017;13:3501-3507.

11. Axelsson TA, Hrafnkelsson J, Olafsdottir EJ, Jonasson JG. Tall cell variant of papillary thyroid carcinoma: a population-based study in 
Iceland. Thyroid 2015;25:216-220.

12. Hawk WA, Hazard JB. The many appearances of papillary carcinoma of the thyroid. Cleve Clin Q 1976;43:207-215.

13. Morris LG, Shaha AR, Tuttle RM, Sikora AG, Ganly I. Tall-cell variant of papillary thyroid carcinoma: a matched-pair analysis of survival. Thyroid 2010;20:153-158.

14. Ito $Y$, Hirokawa $M$, Fukushima $M$, Inoue $H$, Yabuta $T$, Uruno $T$, et al. Prevalence and prognostic significance of poor differentiation and tall cell variant in papillary carcinoma in Japan. World J Surg 2008;32:1535-1543.

15. Kazaure HS, Roman SA, Sosa JA. Aggressive variants of papillary thyroid cancer: incidence, characteristics and predictors of survival among 43,738 patients. Ann Surg Oncol 2012;19:1874-1880.

16. Xing M, Westra WH, Tufano RP, Cohen Y, Rosenbaum E, Rhoden $\mathrm{KJ}$, et al. BRAF mutation predicts a poorer clinical prognosis for papillary thyroid cancer. J Clin Endocrinol Metab 2005;90:63736379.

17. Liu X, Bishop J, Shan Y, Pai S, Liu D, Murugan AK, et al. Highly prevalent TERT promoter mutations in aggressive thyroid cancers. Endocr Relat Cancer 2013;20:603-610.

18. Dettmer MS, Schmitt A, Steinert H, Capper D, Moch H, Komminoth $P$, et al. Tall cell papillary thyroid carcinoma: new diagnostic criteria and mutations in BRAF and TERT. Endocr Relat Cancer 2015;22:419-429.

19. Choi YJ, Shin JH, Kim JH, Jung SL, Son EJ, Oh YL. Tall cell variant of papillary thyroid carcinoma: sonographic and clinical findings. J Ultrasound Med 2011;30:853-858.

20. Baek HJ, Kim DW, Shin GW, Heo YJ, Baek JW, Lee YJ, et al. Ultrasonographic features of papillary thyroid carcinomas according to their subtypes. Front Endocrinol (Lausanne) 2018;9:223.

21. Lloyd RV, Osamura RY, Kloppel G, Rosai J. WHO classification of tumours of endocrine organs. 4th ed. Lyon: IARC Press, 2017.

22. Haugen BR, Alexander EK, Bible KC, Doherty GM, Mandel SJ, Nikiforov YE, et al. 2015 American Thyroid Association management guidelines for adult patients with thyroid nodules and differentiated thyroid cancer: the American Thyroid Association Guidelines Task Force on Thyroid Nodules and Differentiated Thyroid Cancer. Thyroid 2016;26:1-133.

23. Ha EJ, Chung SR, Na DG, Ahn HS, Chung J, Lee JY, et al. 2021 Korean Thyroid Imaging Reporting and Data System and ImagingBased Management of Thyroid Nodules: Korean Society of Thyroid Radiology Consensus Statement and Recommendations. Korean I Radiol 2021;22:2094-2123.

24. Amin MB, Edge S, Greene FL, Byrd DR, Brookland RK, Washington MK, et al. AJCC cancer staging manual. New York: Springer, 2017.

25. Shin JH, Baek JH, Chung J, Ha EJ, Kim JH, Lee YH, et al. Ultrasonography diagnosis and imaging-based management of thyroid nodules: revised Korean Society of Thyroid Radiology Consensus Statement and Recommendations. Korean J Radio 2016;17:370-395.

26. Lee WK, Lee J, Kim H, Lee SG, Choi SH, Jeong S, et al. Peripheral location and infiltrative margin predict invasive features of papillary thyroid microcarcinoma. Eur J Endocrinol 2019;181:139-149.

27. Niemeier LA, Kuffner Akatsu H, Song C, Carty SE, Hodak SP, Yip $L$, et al. A combined molecular-pathologic score improves risk stratification of thyroid papillary microcarcinoma. Cancer 2012;118:2069-2077.

28. Tallini G, De Leo A, Repaci A, de Biase D, Bacchi Reggiani ML, Di Nanni $D$, et al. Does the site of origin of the microcarcinoma with respect to the thyroid surface matter? A multicenter pathologic and clinical study for risk stratification. Cancers (Basel) 2020;12:246.

29. Jiang J, Lu H. Immediate surgery might be a better option for subcapsular thyroid microcarcinomas. Int J Endocrinol 2019:2019:3619864.

30. Ito $Y$, Miyauchi A. Active surveillance as first-line management of papillary microcarcinoma. Annu Rev Med 2019;70:369-379.

31. Leboulleux S, Tuttle RM, Pacini F, Schlumberger M. Papillary thyroid microcarcinoma: time to shift from surgery to active surveillance? Lancet Diabetes Endocrinol 2016:4:933-942. 